\title{
Comparison of Postoperative Analgesic Efficacy of Penile Block, Caudal Block and Intravenous Paracetamol for Circumcision: A prospective Randomized Study
}

Ahmet Hakan Haliloglu, Mehmet Ilker Gokce, Semih Tangal, Mehmet Salih Boga, Hakan Tapar, Ebru Aladag

Ufuk University, Department of Urology Faculty of Medicine (AHH, ST, SB, MSB), Ankara, Department of Urology Sorgun State Hospital (MIG), Yozgat and Department of Anesthesiology Sorgun State Hospital (HT, EA), Yozgat, Turkey

\section{ABSTRACT}

Purpose: To evaluate the postoperative analgesic efficacy of penile block, caudal block and intravenous paracetamol administration following circumcision.

Materials and Methods: In this prospective randomized study a total of 159 patients underwent circumcision under general anesthesia at urology clinic of Ufuk University Faculty of Medicine and Sorgun State Hospital between May 2012 and September 2012. The patients were randomized to three groups to receive penile block (Group 1), caudal block (Group 2) and intravenous paracetamol administration (group 3). Pain measurement of the patients was done via CHEOPS scoring system at 30,60,120 and 180 minutes postoperatively and compared. Statistical tests were performed with a conventional statistics program and statistical significance was set at a $p$ value of $<0.05$.

Results: The mean age of the patients was 5.7 years. Patients in group 1 had significantly lower pain score at 30 minutes compared to other two groups. At 60 minutes groups 1 and 2 had significantly lower score compared to group 3. At 120 and 180 minutes no difference between the groups was observed. No significant major complications were observed in all 3 groups.

Conclusion: Penile block and caudal block provide similar pain scores and painless postoperative periods after circumcision under general anesthesia. Intravenous paracetamol is insufficient at the early postoperative period. The three procedures were shown to be safe for analgesia following circumcision.

\section{ARTICLE INFO}

\section{Key words:}

Circumcision, Male; Analgesia; Penis

Int Braz J Urol. 2013; 39: 551-7

Submitted for publication: January 25, 2013

Accepted after revision: June 12, 2013

\section{INTRODUCTION}

Penile surgery constitutes an important portion of pediatric urological surgery. Postoperative analgesia is an important issue especially in the pediatric population. Successfull pain relief decreases morbidity, and mobilization in the early postoperative period decreases the need for narcotic analgesics (1).

Penile block, caudal block, penile ring infiltration, topical local anesthetic application and administration of paracetamol are commonly employed for pain relief after penile surgery (2). Regional techniques were shown to be more 
effective than systemic opioids, non-steroid anti-inflammatory drugs, and acetaminophene for postoperative analgesia in circumcision (3). Circumcision is the most commonly performed penile surgery in Turkey due to religious traditions. Postoperative pain is an important problem after circumcision and its relief is necessary.

Measurement of pain in pediatric population is difficult and it is mainly obtained by observation of some characteristics and habbits like facial impressions and motor movements. Children's Hospital of Eastern Ontorio Pain Scale (CHEOPS) has been developed for quantification of pain in children (4).

The current literature lacks comparative studies of postoperative analgesia in penile surgery in terms of efficacy and safety. In this prospective randomized double blind study, we aimed to compare efficacy and safety of three analgesic procedures: penile block, caudal block and intravenous paracetamol administration.

\section{MATERIALS AND METHODS}

Patients applied to urology outpatient clinic of Ufuk University Faculty of Medicine and Sorgun State Hospital between May 2012 and September 2012 for circumcision were enrolled in the study. Preoperative evaluation was done based on ASA Physical Status Classification. Parents of all patients were informed about the procedure and written informed consent was obtained from all parents. Circumcision was performed under general anesthesia.

\section{Inclusion \& exclusion criteria}

Inclusion criteria included patients older than 12 months and younger than 7 years, ASA Physical Status Classification I, normal level of liver enzymes, no other penile deformity, no spinal cord defect. Patients with any other penile deformity, elevated liver enzymes, any comorbid condition, history of seizures, neuromuscular disorder, spinal cord defect and cronic pain were excluded.

Preoperatively patients were randomized to three groups. Group 1 included patients who received penile block, group 2 consisted of caudal block patients and group 3 consisted of patients who received intravenous paracetamol. Postoperative pain was measured by CHEOPS scale (Table-1). Operative time, patients age, CHEOPS scores at postoperative 30,60,120 and 180 minutes and complications and rescue analgesia rates were recorded. Primary outcome measures were CHEOPS scores and secondary outcomes were complication and rescue analgesia rates.

Caudal block was performed by injection of $0.2 \mathrm{~mL} / \mathrm{kg}$ bupivacaine by $18-$ Gauge Thuohy needle through the sacral hiatus. Caudal block was performed by the anesthesiologist after the induction of general anesthesia and before circumcision procedure. Penile block was performed by injection of $0.2 \mathrm{~mL} / \mathrm{kg} 0.25 \%$ bupivacaine by 23 gauge needle. Penile block was performed by the surgeon, after cutting the foreskin before performing the stitches. Injection was performed at 2 and 10 o'clock positions by two separate and equal injections. Intravenous $(15 \mathrm{mg} / \mathrm{kg}$ ) was administered $(15 \mathrm{mg} / \mathrm{kg}$ ) just after the procedure at the operating room. A total of 4 surgeons and 3 anesthesiologists performed the procedures.

\section{Sample size}

Sample size was estimated as 135 (45 patients in each group) with power of 0.80 and an effect size of 35\% (5 points difference in CHEOPS score). Effect size of 35\% is accepted because 4 points of difference in CHEOPS score is accepted as significant difference and maximum points in CHEOPS score is $13(4 / 13=30.7 \%)$.

\section{Statistical analysis \& Randomization}

Randomization was performed by NCSS software from a single centre. Statistical analysis was performed by SPSS ver.15.0. Kolmogorov-Simirnov test was performed to determine normal distribution. One-way ANOVA test was used for comparison of groups. P value of 0.05 was used for statistical significance. CHEOPS scores were measured by a single nurse at each hospital. Physicians performing the penile or caudal block were not involved in CHEOPS score measurement. 


\section{Table 1 - Children's Hospital Eastern Ontario Pain Scale (CHEOPS).}

\begin{tabular}{|c|c|c|c|}
\hline Item & Behavioral & Definition & Score \\
\hline \multirow[t]{4}{*}{ Cry } & No cry & Child is not crying. & 1 \\
\hline & Moaning & Child is moaning or quietly vocalizing silent cry. & 2 \\
\hline & Crying & Child is crying, but the cry is gentle or whimpering & 2 \\
\hline & Scream & $\begin{array}{l}\text { Child is in a full-lunged cry; sobbing; may be scored with complaint or } \\
\text { without complaint }\end{array}$ & 3 \\
\hline \multirow[t]{3}{*}{ Facial } & Composed & Neutral facial expression & 1 \\
\hline & Grimace & Score only if definite negative facial expression. & 2 \\
\hline & Smiling & Score only if definite positive facial expression. & 0 \\
\hline \multirow[t]{5}{*}{ Child Verbal } & None & Child not talking. & 1 \\
\hline & Other complaints & $\begin{array}{l}\text { Child complains, but not about pain, e.g., "I want to see mommy" of } \\
\text { "I am thirsty". }\end{array}$ & 1 \\
\hline & Pain complaints & Child complains about pain. & 2 \\
\hline & Both complaints & $\begin{array}{l}\text { Child complains about pain and about other things, e.g., "It hurts; I } \\
\text { want my mommy". }\end{array}$ & 2 \\
\hline & Positive & $\begin{array}{l}\text { Child makes any positive statement or talks about others things } \\
\text { without complaint. }\end{array}$ & 0 \\
\hline \multirow[t]{6}{*}{ Torso } & Neutral & Body (not limbs) is at rest; torso is inactive. & 1 \\
\hline & Shifting & Body is in motion in a shifting or serpentine fashion & 2 \\
\hline & Tense & Body is arched or rigid. & 2 \\
\hline & Shivering & Body is shuddering or shaking involuntarily & 2 \\
\hline & Upright & Child is in a vertical or upright position & 2 \\
\hline & Restrained & Body is restrained. & 2 \\
\hline \multirow[t]{5}{*}{ Touch } & Not touching & Child is not touching or grabbing at wound. & 1 \\
\hline & Reach & Child is reaching for but not touching wound. & 2 \\
\hline & Touch & Child is gently touching wound or wound area & 2 \\
\hline & Grab & Child is grabbing vigorously at wound. & 2 \\
\hline & Restrained & Child's arms are restrained & 2 \\
\hline \multirow[t]{5}{*}{ Legs } & Neutral & $\begin{array}{l}\text { Legs may be in any position but are relaxed; includes gentle swim- } \\
\text { ming or separate-like movements. }\end{array}$ & 1 \\
\hline & Squirm/kicking & $\begin{array}{l}\text { Definitive uneasy or restless movements in the legs and/or striking out } \\
\qquad \text { with foot or feet. }\end{array}$ & 2 \\
\hline & Drawn up/tensed & Legs tensed and/or pulled up tightly to body and kept there. & 2 \\
\hline & Standing & Standing, crouching or kneeling. & 2 \\
\hline & Restrained & Child's legs are being held down. & 2 \\
\hline
\end{tabular}




\section{RESULTS}

A total of 166 patients were randomized for the study and data of 159 patients were evaluated. Seven patients were excluded from the study. In 4 of these patients cardiac arrythmia was observed during anesthesia induction and their circumcisions were postponed. In the other 3 patients laryngeal spasm developed after the procedure and as anesthesia resolution was delayed in these patients, their pain scoring was tought to have been effected so they were excluded. The flow of participants is given in Figure-1.

The mean age of the population was 3.7 years and mean operation time was 22.8 minutes. There were 46 patients in group 1, 58 patients in group 2 and 55 patients in group 3. There were no significant difference between the groups in terms of age (3.58 vs. 3.84, $\mathrm{p}=0.259$ ) and operation time (22.7 vs. 22.5 vs. $23.1, \mathrm{p}=0.488$ ).

When the CHEOPS scores were compared, in the very early postoperative period of $30 \mathrm{minu}$ tes, the mean CHEOPS scores were 10.95, 7.03 and 11.31 in group 1, group 2 and group 3, respectively. The CHEOPS score in group 2 was significantly lower compared to group 1 and group 3 ( $p=$
0.0001). However, the difference between group 1 and group 3 was not statistically significant ( $p=$ 0.477). The mean 60 minutes CHEOPS scores were 5.8, 5.0 and 10.01 in group 1, group 2 and group 3 respectively. The difference between group 1 and group 2 was not significant (0.189), however these two groups have significantly lower values compared to group 3.

In the late postoperative period, when CHEOPS scores were measured at 120 minutes, the mean scores of the three groups were 4.45, 4.81 and 4.82 and the difference between the three groups was not significant. Similarly, the mean CHEOPS scores at 180 minutes were almost identical and no significant difference between the three groups was observed. The CHEOPS scores are summarized in Table-2 and Figure-2.

In all three groups, no major complication (arrhythmia, hypotension, shock, or seizures) after any procedure was noted. No edema, hematoma, postoperative agitation, motor block, or urinary retention were seen in either group. Only minor bleeding occured in one patient after performing penile block and it resolved wtih simple compression without any significant hematoma. No severe bleeding occurred during surgery.

Figure 1 - Flow of participants.

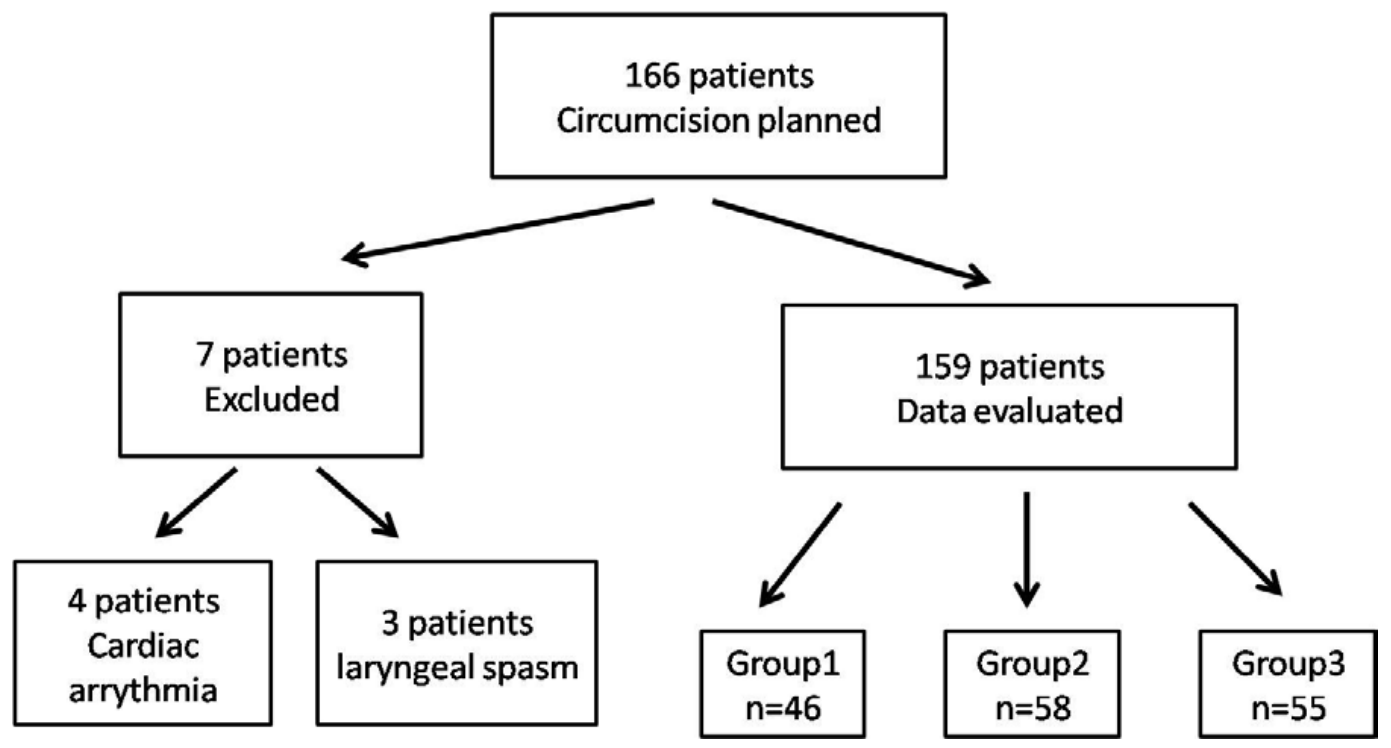


Figure 2 - CHEOPS Scores of the three groups at certain time intervals.

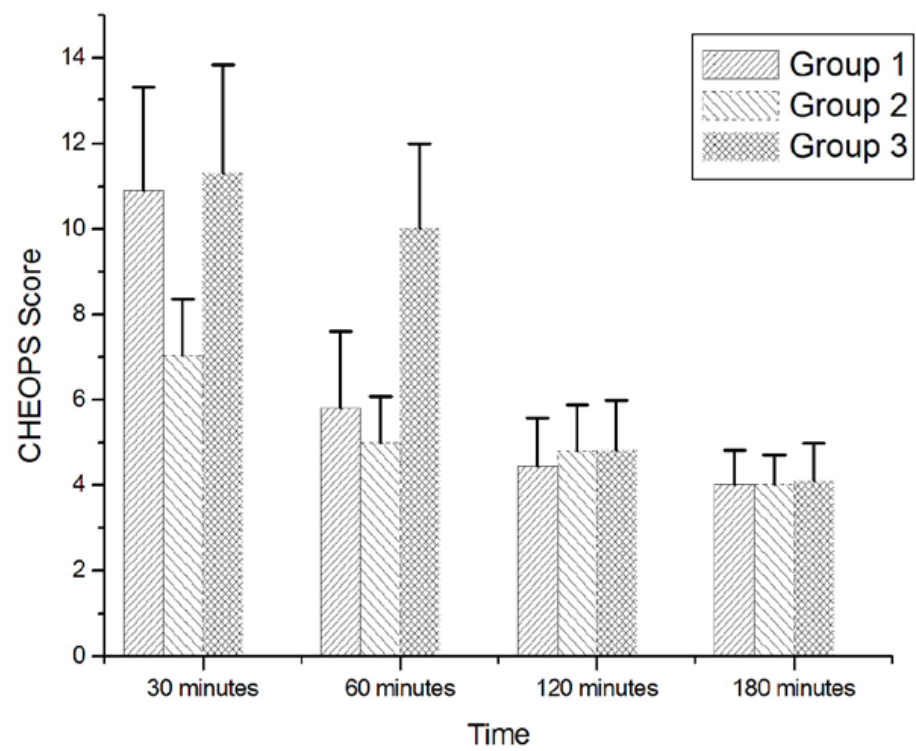

Table 2 - CHEOPS scores of the three groups at certain time intervals.

\begin{tabular}{|c|c|c|c|c|}
\hline Parameter & Group 1 & Group 2 & Group 3 & $P$ value \\
\hline CHEOPS $30 \mathrm{~min}$. & 10.9 & 7.03 & 11.3 & $\begin{array}{l}\text { Group } 1 \text { vs Group 2: } 0.0001 \\
\text { Group } 2 \text { vs Group 3: } 0.0001 \\
\text { Group } 1 \text { vs Group 3: } 0.477\end{array}$ \\
\hline CHEOPS $60 \mathrm{~min}$. & 5.8 & 5.0 & 10.01 & $\begin{array}{l}\text { Group } 1 \text { vs Group 2: } 0.189 \\
\text { Group } 2 \text { vs Group 3: } 0.0001 \\
\text { Group } 1 \text { vs Group 3: } 0.0001\end{array}$ \\
\hline CHEOPS $120 \mathrm{~min}$. & 4.45 & 4.81 & 4.82 & $\begin{array}{l}\text { Group } 1 \text { vs Group 2: } 0.344 \\
\text { Group } 2 \text { vs Group 3: } 0.451 \\
\text { Group } 1 \text { vs Group 3: } 0.477\end{array}$ \\
\hline CHEOPS $180 \mathrm{~min}$. & 4.02 & 4.01 & 4.09 & $\begin{array}{l}\text { Group } 1 \text { vs Group 2: } 0.998 \\
\text { Group } 2 \text { vs Group 3: } 0.954 \\
\text { Group } 1 \text { vs Group 3: } 0.950\end{array}$ \\
\hline
\end{tabular}

\section{DISCUSSION}

Circumcision is the most common surgical procedure carried out in boys globally $(5,6)$. Minimizing complications and pain is an important issue and vast amount of research was done on various anaesthetic and analgesic techniques (7). Systemic analgesics and regional anaesthetic techniques with various efficacies have been used for pain relief after circumcision including topical analgesics, caudal block and penile block. 
Quality of postoperative analgesic methods have been studied in a number of studies previously. In some of these studies two methods were found to be equally effective, however significant difference was observed in others. In our study, efficacy of penile block, caudal block and intravenous paracetamol was compared in circumcision cases under general anesthesia.

Postoperative analgesic efficacy and supplementary analgesic needs of penile block and caudal block were found to be similar in the prospective randomized study of Beyaz et al. (8). In an other study comparing penile block and caudal block, the time to first analgesia requirement was the primary outcome and no difference was detected between the two procedures (9). Similarly, In the study of Weksler et al. the authors found out that penile and caudal block were equally effective for postcircumcision analgesia and neither was associated with serious complications (2).

In an other study conducted by Naja et al. circumcision was performed under regional anesthesia and postoperative pain scores were also recorded. The authors recorded higher postoperative pain scores in penile block group. However, the efficacy of penile block in this study was low: 20\% of the patients needed additional anesthesia (10). In their retrospective study, Sandemann et al. found that penile block patients required more postoperative analgesics compared to caudal block patients. However, the difference was not observed when penile block was applied with ultrasound guidance. Therefore, the difference seems to be related to quality of the procedure (11).

In our study, pain scores were taken at different time intervals and when the techniques were compared, caudal block was found to be more effective at the very early postoperative period ( 30 minutes) than penile block. The difference was not significant at 60,120 and $180 \mathrm{mi}-$ nutes. This may be associated with application time of penile block. It is performed in the middle of surgery therefore its efficacy may not be so prominent at 30 minutes. Also, when intravenous paracetamol and penile block were compared there were no differences at 30 minutes and this finding also suppors the delay in efficacy of penile block.

In previous studies, postoperative analgesia duration was reported to be over 300 minutes (12). Therefore in our study, the pain follow up was limited to 180 minutes.

Efficacy of intravenous paracetamol after circumcision has been studied previously. Paracetamol was not found to ameliorate the immediate postoperative pain in children after circumscion (13). In our study, CHEOPS scores at 30 minutes and 60 minutes were 11.3 and 10.01 respectively and significant decrease started thereafter, 4.81 and 4.09 at 120 and $180 \mathrm{mi}-$ nutes respectively. The difference of intravenous paracetamol and caudal block was significant at 30 and 60 minutes and no significant difference was observed at 120 and 180 minutes. When intravenous paracetamol and penile block were compared, no significant difference was observed at 30 minutes. This is probably due to ameliorated analgesic effect of both methods because there was a siginificant difference at 60 minutes postoperatively. The significant difference was observed at 120 and 180 minutes measurements.

Major complication rates of caudal block or penile block were found to be very low in previous studies $(3,14)$. Similarly no technical difficulties, major complications, or neurological sequelae during penile block or caudal block was observed in our population. However, minor complication rates were more prominent in previous studies reaching up 8.3\%. The frequently encountered minor complications were edema, hematoma and vomiting. Only minor bleeding which resolved by simple compression was observed in two patients following penile block.

An important drawback of our study was the lack of a placebo group, in a study where pain was measured subjectively. However performing the trial with a control group seemed unethical as the trial was conducted in pediatric population and any postoperative analgesic treatment was shown to be effective after circumcision. Number of patients is quite sufficient to detect even small amount of difference between the groups and the surgeons were blinded to pain scoring issue. 


\section{CONCLUSIONS}

Penile block and caudal block provided similar pain scores and painless postoperative periods after circumcision under general anesthesia. For a better early postoperative analgesia penile block should be performed at the beginning of the operation. Intravenous paracetamol was insufficient at the early postoperative period, however its efficacy reached the level of regional analgesic procedures after 120 minutes. No major complications were observed and minor complication rates were acceptable. Both penile block and caudal block were effective, safe, simple, and easy to perform to achieve successfull postoperative analgesia after circumcision.

\section{ACKNOWLEDGMENTS}

\section{Ontorio Pain Scale}

\section{CONFLICT OF INTEREST}

None declared.

\section{REFERENCES}

1. Semsroth M, Gabriel A, Sauberer A, Wuppinger G: Regional anesthetic procedures in pediatric anesthesia. Anaesthesist. 1994; 43: 55-72.

2. Weksler N, Atias I, Klein M, Rosenztsveig V, Ovadia L, Gurman GM: Is penile block better than caudal epidural block for postcircumcision analgesia? J Anesth. 2005; 19: 36-9.

3. Telgarsky B, Karovic D, Wassermann O, Ogibovicova E, Csomor D, Koppl J, et al.: Penile block in children, our first experience. Bratisl Lek Listy. 2006; 107: 320-2.

4. Gregory GA: Pediatric Anesthesia 3th ed., New York:Churchill Livingstone Inc., 1994: 743-71.

5. Al-Ghazo MA, Banihani KE: Circumcision revision in male children. Int Braz J Urol. 2006; 32: 454-8.
6. Lau JT: Penile block for pain relief after circumcision in children. A randomized, prospective trial. Am J Surg. 1984; 147: 797-9.

7. Alanis MC, Lucidi RS: Neonatal circumcision: a review of the world's oldest and most controversial operation. Obstet Gynecol Surv. 2004; 59: 379-95.

8. Beyaz SG: Comparison of Postoperative Analgesic Efficacy of Caudal Block versus Dorsal Penile Nerve Block with Levobupivacaine forCircumcision in Children. Korean $\mathrm{J}$ Pain. 2011; 24: 31-5.

9. Margetts L, Carr A, McFadyen G, Lambert A: A comparison of caudal bupivacaine and ketamine with penile block for paediatric circumcision. Eur J Anaesthesiol. 2008; 25: 1009-13.

10. Naja Z, Al-Tannir MA, Faysal W, Daoud N, Ziade F, El-Rajab $\mathrm{M}$ : A comparison of pudendal block vs dorsal penile nerve block for circumcision in children: a randomised controlled trial. Anaesthesia. 2011; 66: 802-7.

11. Sandeman DJ, Reiner D, Dilley AV, Bennett MH, Kelly KJ: A retrospective audit of three different regional anaesthetic techniques for circumcision in children. Anaesth Intensive Care. 2010; 38: 519-24.

12. Faraoni $D$, Gilbeau $A$, Lingier $P$, Barvais $L$, Engelman $E$, Hennart D: Does ultrasound guidance improve the efficacy of dorsal penile nerve block in children? Paediatr Anaesth. 2010; 20: $931-6$

13. Howard CR, Howard FM, Weitzman ML: Acetaminophen analgesia in neonatal circumcision: the effect on pain. Pediatrics. 1994; 93: 641-6.

14. Uguralp S, Mutus M, Koroglu A, Gurbuz N, Koltuksuz U, Demircan M: Regional anesthesia is a good alternative to general anesthesia in pediatric surgery: Experience in 1,554 children. J Pediatr Surg. 2002; 37: 610-3.

Correspondence address:

Dr. Mehmet Ilker Gokce Sorgun State Hospital Department of Urology Sorgun Devlet Hastanesi, Sorgun, Yozgat, Turkey Fax: +0031 2 311-2167 E-mail: migokce@yahoo.com 